\title{
Characteristics of coastline changes in mainland China since the early 1940s
}

\author{
HOU XiYong ${ }^{1 *}$, WU Ting ${ }^{1,2}$, HOU Wan ${ }^{1,2}$, CHEN Qing ${ }^{1,2}$, \\ WANG YuanDong ${ }^{1,2} \&$ YU LiangJu $^{1}$ \\ ${ }^{1}$ Yantai Institute of Coastal Zone Research, Chinese Academy of Sciences, Yantai 264003, China, \\ ${ }^{2}$ University of Chinese Academy of Sciences, Beijing 100049, China
}

Received October 16, 2015; accepted April 18, 2016; published online June 20, 2016

\begin{abstract}
Based on multi-temporal topographic maps, remote sensing images and field surveys covering the entire coastal zone of mainland China, the coastlines of six periods since the early 1940s were extracted. Coastline changes over the last 70 years were then analyzed in terms of coastline structure, coastline fractals, coastline change rates, land-sea patterns, and bay areas. The results showed that mainland coastline structure changed dramatically, and due to the significant coastline artificialization mainly driven by sea reclamation and coastal engineering, the remaining natural coastline merely accounts for less than one third at present. Coastline fractal dimension represented an overall spatial pattern of "north < entirety < south"; however, the discrepancy between the north and south coast was apparently narrowed due to dramatic coastline artificialization of northern China which in turn altered the whole pattern. Patterns and processes of land-sea interchange along the mainland coast were complex and varied spatially and temporally, with over $68 \%$ advancing toward sea and $22 \%$ retreating toward land. The net growth of land area was nearly $14.2 \times 10^{3} \mathrm{~km}^{2}$ with an average growth rate of $202.82 \mathrm{~km}^{2} \mathrm{a}^{-1}$; and coast retreat was characterized by area decrease of 93 bays with a magnitude of $10.1 \times 10^{3} \mathrm{~km}^{2}$ and an average shrinking rate up to $18.19 \%$ or an average shrinking speed up to $144.20 \mathrm{~km}^{2} \mathrm{a}^{-1}$, among which the total area of Bohai shrunk by $7.06 \%$, with an average annual loss amounting to $82 \mathrm{~km}^{2}$. The dramatic coastline changes along mainland China have brought about kinds of challenges to the coastal environment, therefore the integrated management, effective environment protection and sustainable utilization of coastlines is urgent.
\end{abstract}

Keywords China, Mainland coastline, Coastline structure, Coastline fractal dimension, Coastline change rate, Land-Sea change, Bay area

Citation: Hou X Y, Wu T, Hou W, Chen Q, Wang Y D, Yu L J. 2016. Characteristics of coastline changes in mainland China since the early 1940s. Science China Earth Sciences, 59: 1791-1802, doi: 10.1007/s11430-016-5317-5

\section{Introduction}

Worldwide coastline changes are characterized by increasing erosion or drastic expansion toward sea due to various environmental processes at the global scale such as climate change and sea level rise (Cooper et al., 2008; Zhuang et al.,

*Corresponding author (email: xyhou@yic.ac.cn)
2008; Peduzzi et al., 2012), and coastal processes including marine dynamics and local climate variation (Yıldırım et al., 2010; St-hilaire-Gravel et al., 2012; Ranasinghe et al., 2013; Kish and Donoghue, 2013), as well as anthropological activities (i.e., marine reclamation and coastal protection) (Slott et al., 2010; Zhu and Xu, 2012; Mujabar and Chandrasekar, 2013). At least $70 \%$ beaches worldwide are in chronic erosion (Dar and Dar, 2009). Coastal erosion is also prevalent in China, with more than one third of shore- 
lines being eroded (Ji, 1996). However, population aggregation and economic growth in coastal zones accelerated the development of land reclamation from sea, which can be found in Netherlands, Japan, South Korea, USA, Brazil and South Africa. In China, coastal development and utilization has been intensified since the 1950s, consequently, both coastline artificialization and coastline expansion have been accelerated. While coast erosion could damage lands with economic values, such as farmlands, salt pans and aquaculture ponds, destabilize buildings with cultural values, inundate and damage the coastal wetland ecosystem, or even destroy the coastal protection structures (e.g., coastal levees) and other infrastructural facilities (Ji, 1996), artificial modification and seaward expansion of shorelines also cause unprecedented risks to eco-environmental conditions of coastal zone: industrial and domestic wastewater leading to severe seawater eutrophication (Cui et al., 2005); land subsidence due to construction of large seawalls (Feng and Niu, 2004) and wetland degradation (Guan et al., 2008); and coastal reclamation projects encroaching the breeding sites or habitats of aquatic or wetland flora and fauna (Crowell et al., 2010). Under such context, analyzing the spatiotemporal characteristics of coastline changes, identifying vulnerable coastal sections in which coastline erosion or expansion is stronger, and exploring their impacts on coastal ecosystem and environment to provide information and policy-making supports for disaster prevention and reduction efforts, and to protect residents' lives and properties, have drawn increasing worldwide attention (Roeland and Piet, 1995; Moore et al., 1999; Morton and Mckenna, 1999; Kuleli, 2010; Kish and Donoghue, 2013).

China's coast zone is one of the regions with fast growth and great economic vitality in the world. With only $15 \%$ area of national land, it hosts more than $70 \%$ of medium-to-large cities and nearly $40 \%$ population, and produces over $61 \%$ of the national GDP (Zhang et al., 2015). Since the early 1950s, the coastline of mainland China has undergone drastic changes, and coastline utilization has increased continuously and significantly (Wu et al., 2014), especially since China adopted the "Reform and Opening up" policies, the coastal development mode has evolved remarkably and human activities have become the main factor dominating shoreline changes (Gao et al., 2013). For instance, the magnitude of coastal reclamation in China was staggering, nearly $300 \mathrm{~km}^{2}$ of lands were reclaimed from sea every year during the period of Tenth Five-Year Plan (2001-2005), and up to $700 \mathrm{~km}^{2}$ during the 11th Five-Year Plan (2006-2010) (Zhu and Xu, 2011). By October 2012, the sea reclamation area reserved for economy construction by 2020 that has been approved by the central government in the form of marine function zoning plans in 11 provinces/municipali- ties/ autonomous regions had added up to $2469.03 \mathrm{~km}^{2}$. However, due to the intrinsic vulnerability, coastal zone is very sensitive to climate change and human activities. Coastal reclamation and drastic shoreline altera- tions have induced many problems including swift mode alternation of land-sea interactions, increase of land-based pollution to the sea, continuous reduction of coastal wetlands, and severe degradation of coastal ecosystem functions and services. Therefore, in order to improve abilities of coastal resource utilization and environment protection as well as sustainability of coastal society development, it is of great importance to reveal the ecological and environmental impacts of coastline changes through location and property monitoring of coastline, hotspots detection and temporal tendency analysis of coastline change. In this study, multitemporal coastline data of mainland China were constructed based on remote sensing and GIS techniques, and spatio-temporal characteristics of coastline changes were analyzed from perspectives of coastline structure, coastline fractal dimension, coastline change rate, land-sea pattern and bay areas, etc., which could provide valuable information and policy-making supports for integrated management of resources and environment in China's coastal zone.

\section{Study area}

China's mainland coastline stretches from the Yalu River Estuary at the China-North Korea border in the north to the Beilun River Estuary at the Sino-Vietnamese border in the south, spanning a vast region of nearly 20 latitudes and three climatic zones (i.e., warm temperate zone, subtropical zone, and tropical zone). From north to south, the coastline extends via Bohai Sea, Yellow Sea, East China Sea and South China Sea, sequentially, as well as 12 provinces/ municipalities/autonomous administrative regions, i.e., Liaoning, Hebei, Tianjin, Shandong, Jiangsu, Shanghai, Zhejiang, Fujian, Guangdong, Hong Kong, Macao, and Guangxi (Figure 1).

Coastal zones of mainland China, a major part of the whole country, have a typical East Asian monsoon climate and suffer from severe natural disasters caused by typhoon accompanied by strong wind, rainstorm, and storm surge. Topographically, these coastal regions are located on the lower third terrace of mainland terrain, where different landforms (e.g., coastal low-lying plains, estuarine deltas, low mountains and hills, and bays) distributed alternatively. According to morphology and origin, there are three types of mainland coastline which include mountainous or hilly coast, plain coast and biological coast. Separated by Hangzhou Bay, the mainland coast in China includes two parts: the northern part is dominated by plain coast, while the southern part is mainly featured by hilly and biological coast. Plain coasts consist of deltas, sandy beaches, and muddy shores, among which, deltas mainly develop in large estuarine area like Liaohe, Yellow River, Yangtze and Pearl rivers, and typical muddy coasts lie along Bohai Bay and on Northern Jiangsu Plain. Hilly coasts comprise of rocky coasts, sandy coasts and fault coasts, among which, rocky 


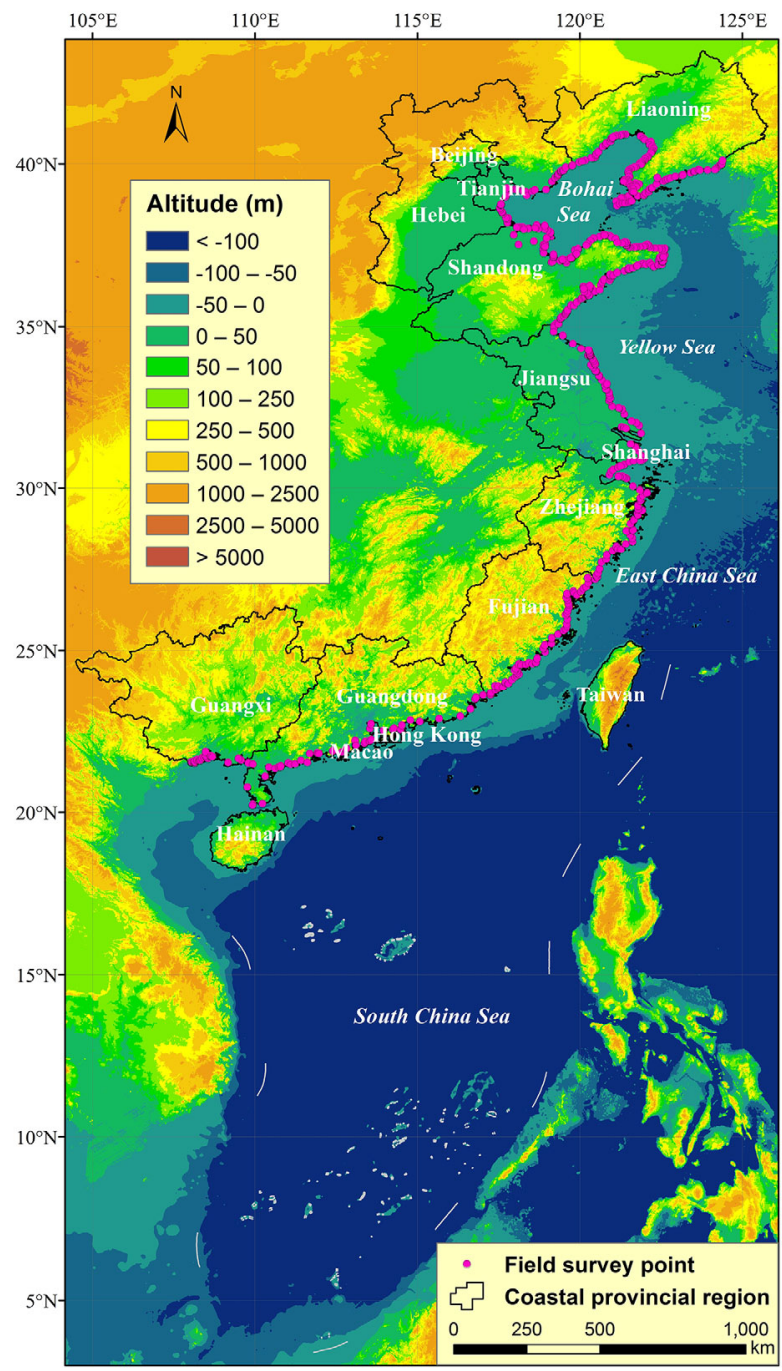

Figure 1 Spatial distribution of field survey points along mainland coastline in China.

coasts are widely distributed in Liaodong Peninsula, Jiaodong Peninsula and south of Hangzhou Bay, and sandy coasts distributed widely except Jiangsu Province. Biological coasts are mainly distributed in tropical and subtropical zones, including coral reef and mangrove coasts lying south of Fujian Province.

\section{Methods of coastline extraction}

\subsection{Definition and classification of coastline}

The physical land-sea boundary is dynamic and instantaneous, therefore, the proxies of coastline are often employed in practice, such as mean high water line (MHWL), instantaneous high water line (IHWL), low water line (LWL), wet/dry boundary, vegetation line, debris line, and beach ridge line (Boak and Turner, 2005). High water line is usually recognized as the best coastline indicator since it can be identified easily both in the field, and from remote sensing images or aerial photographs, and thus MHWL is commonly used as the indicator in cartography and long term research, for example, it was selected as the wet/dry boundary in 908 special project "Satellite remote sensing survey technologies in coastal zones of islands" by State Oceanic Administration. The high water line was also adopted in this paper, in detail, coastline was divided into 11 categories according to their substrate and utilization mode (Table 1), and then, identification criteria of coastline in different geomorphologic sites and corresponding interpretation standards on remote sensing images were established based on information and knowledge achieved from field surveys.

\subsection{Data sources for coastline extraction}

Maps and remote sensing images since the early 1940s were pre-processed, integrated and managed in GIS and were then employed to extract multi-temporal coastline data of mainland China over the past 70 years. These maps and images include: (1) 48 topographic maps with a scale of $1: 250000$ covering China's coast, compiled by the US Army Map Service during 1904-1945; 275 topographic maps with a scale of $1: 50000$ and 39 topographic maps with a scale of 1:100000 covering China's coast surveyed during 1951-1972, most of these maps were surveyed around 1960 , therefore, they were used to extract coastline dataset of 1960; (2) Landsat TM/ETM+/OLI images with a spatial resolution of $30 \mathrm{~m}$ acquired in 1990, 2000, 2010, and 2014, respectively, covering the entire coast of mainland China, which can be downloaded from website of USGS (United States Geological Survey, http://glovis.usgs.gov/). The Landsat images were used to extract coastline datasets in these four years.

\subsection{Technical specifications of coastline extraction}

Coastlines in the 1940s and 1960s could be easily extracted due to their clear visibility on topographic maps. Location and type of coastlines in 1990, 2000, 2010 and 2014 were visually interpreted and delineated by displaying Landsat TM/ETM+/OLI images in band composite of 543, 743, or 432 in ArcGIS 9.3 with a fixed screen zoom tolerance of $1: 10000$. In detail, classification of coastlines was processed by referring to landforms and surface features nearby; as for location identifying, the rocky coastline is generally delineated at wet/dry boundary on satellite images or baseline of bluff/cliff in situ, the sandy coastline is delineated at beach crest or vegetation line, the muddy coastline is delineated at vegetation line or debris line (the morphology and distribution of tidal creeks can be used as supplementary information), biogenic coastline of vegetation patches is delineated at the sideline to the land side. During the interpretation, sufficient sampling density by cursor mouse was requested to ensure that there was no obvious displacement for the overall and partial interpretation results; sampling 
Table 1 Categories of mainland coastline in China

\begin{tabular}{|c|c|c|}
\hline & Categories & Introduction \\
\hline \multirow{4}{*}{$\begin{array}{l}\text { Natural coast- } \\
\quad \text { line }\end{array}$} & Rocky coastline & $\begin{array}{c}\text { Coastline on rocky coast, and is generally located at the wet/dry boundary, and in the field, it is the baseline of } \\
\text { bluff/cliff }\end{array}$ \\
\hline & Sandy coastline & $\begin{array}{c}\text { Coastline on sandy beach, and is generally located at the beach crest, and in the field, it is usually coincides } \\
\text { with the vegetation line }\end{array}$ \\
\hline & Muddy coastline & $\begin{array}{c}\text { Coastline on muddy or silt coast, and is generally located at vegetation line where distribution pattern of } \\
\text { salt-tolerant plants apparently change, and in the field, it is usually coincides with debris line that is generated } \\
\text { under the effect of onshore current }\end{array}$ \\
\hline & Biogenic coastline & $\begin{array}{c}\text { Coastline on the coast of covered with mangrove, coral reef, or reed, and is generally located at landward side } \\
\text { of the vegetation patch }\end{array}$ \\
\hline \multirow{6}{*}{$\begin{array}{l}\text { Hardened coast- } \\
\quad \text { line }\end{array}$} & Groin and Jetty & $\begin{array}{l}\text { Groin: low wall built out into the sea obliquely to prevent it from washing away sand and stones from beaches } \\
\text { and regulate alongshore current } \\
\text { Jetty: a wall built out into the sea with one side on shore for wave defending }\end{array}$ \\
\hline & Harbor and Wharf & Hardened wall that belong to harbor and wharf \\
\hline & Reclamation & Districts that is being reclaimed \\
\hline & Aquaculture dike & Dikes built for aquaculture \\
\hline & Salt pan dike & Dikes built for salt extraction \\
\hline & Sea wall & Other coastal protection projects that separate land from water \\
\hline
\end{tabular}

points should be densified where coast is tortuous or could be reduced where coast is smooth or straight. At estuary, coastline was produced by protruding points where the river course expands abruptly, or nearest bridges or tidal barrier were identified as shorelines. Cross-sea bridges, linearly connected land-tied islands, or reclaimed areas that have not been enclosed were not treated as mainland coastlines. During the period of 2011-2013, we conducted more than ten field surveys with an accumulated travel distance of $16.3 \times 10^{3} \mathrm{~km}$, collected 578 records of GPS coordinates data, and took more than 6000 photos (Figure 1), which were used for precision control and uncertainty analysis of mainland coastlines extracted from previous procedures (Hou et al., 2014).

\subsection{Uncertainty analysis of coastline position}

Based on the coordinates of control points recorded by GPS during field surveys, perpendicular distances from these points to coastlines of six periods were measured, and mean values, standard deviations (SD) and root mean square errors (RMSE) of the point-to-line distance were then calculated to represent the positional uncertainty of coastlines (Hou et al., 2014). Take RMSE for example, it amounts to $25.23,28.01,23.46,22.15,19.52$ and $19.36 \mathrm{~m}$ in the $1940 \mathrm{~s}$, 1960s, 1990, 2000, 2010, and 2014, respectively, which are all smaller than the intrinsic maximum permissible error depending on their data source in theory.

\section{Characteristics of coastline changes in mainland China}

Coastline changes in mainland China were characterized by coastline structure, coastline fractal dimension, coastline change rate, land and sea pattern, and bay area change in this work.

\subsection{Characteristics of coastline structure change}

Coastline structure refers to the length proportion of various coastlines in a specific region. For natural coast that hasn't been affected by human activities, coastline structure reflects the types, status and properties of coastline as a result of long-term and physical interactions between land and ocean. For coast had been artificialized in various degree due to human activities, coastline structure represents the proportion of natural and artificialized coastlines, i.e., magnitude of coastline utilization and human impacts. Statistics show that in the 1940s, 1960s, 1990, 2000, 2010 and 2014, the total length of mainland coastline was $18.1 \times 10^{3}$, $19.2 \times 10^{3}, 16.5 \times 10^{3}, 17.2 \times 10^{3}, 18.8 \times 10^{3}$ and $19.7 \times 10^{3} \mathrm{~km}$, respectively. Coastline structure changes in mainland China over the past 70 years are shown in Table 2.

In general, mainland coastline in China has been artificialized at a dramatic scale and speed. The length and proportion of natural coastline declined sharply, falling from $14.8 \times 10^{3} \mathrm{~km}(81.70 \%)$ in the early 1940 s to only $6.5 \times 10^{3}$ $\mathrm{km}(32.92 \%)$ in 2014 ; meanwhile artificialized shoreline grew rapidly, rising from $3.3 \times 10^{3} \mathrm{~km}(18.30 \%)$ in the early 1940 s to $13.2 \times 10^{3} \mathrm{~km}(67.08 \%)$ in 2014 . Among artificialized coastlines, groin and jetty, harbor and wharf, reclamation, and aquaculture dikes increased continuously; salt pan dike and sea wall fluctuated drastically but decreased overall; traffic dike grew continuously but its proportion fluctuated slightly. The proportion of sea wall was the highest before the 1990s and followed by salt pan dike, they were subsequently replaced by aquaculture dike and traffic dike after the 1990s, demonstrating the acute impacts of socioeconomic growth, improvement of living standards, technological development, etc. on coastline change.

Statistics of 10 coastal provinces/municipalities/autonomous (coastline of Hong Kong and Macao was combined with that of Guangdong, the same below) further indicated that coastline structure in mainland China exhibited com- 
Table 2 Changes of mainland coastline structure in China (\%)

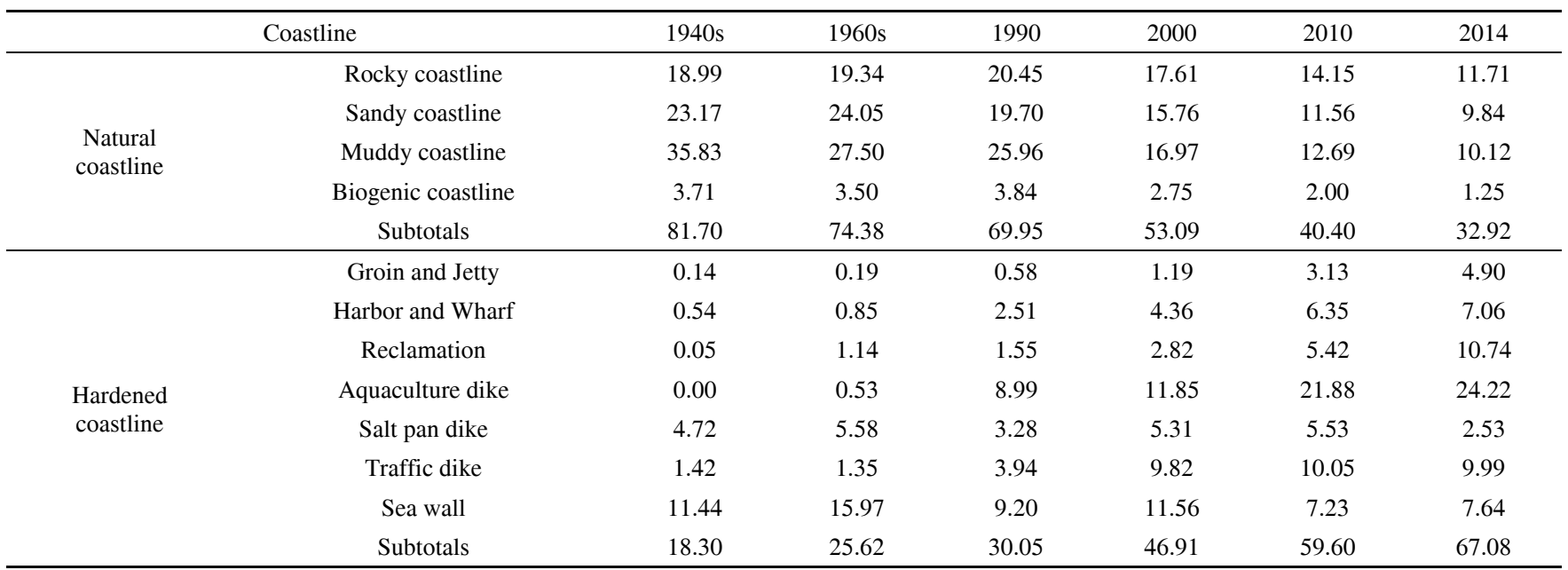

plex spatial patterns and temporal processes. However, the overall trend was the enhancement of coastline artificilization and the northward movement of the hardened coastline centroid. In specific, the ratio of artificialized coastline length to total coastline length was defined as coastline artificialization degree (CAD); CADs in Shanghai and Jiangsu were always higher than that of the whole coastal areas in China all the time; in the early 1940s and 1960s, CADs in Zhejiang and Tianjin were higher than that of the whole coastal area in mainland China; after 1990s, however, CADs in Zhejiang, Fujian, Guangdong (together with Hong Kong and Macao) and Guangxi were lower than that of the whole coastal area, which was just the opposite situation of Liaoning, Hebei, Tianjin, Shandong, Jiangsu and Shanghai; Particularly, CAD in Circum-Bohai Rim since the 2010s was already significantly higher than that in other regions, suggesting coastal zone of Bohai Rim had become the center and the most prominent hotspot of coastal development and coastline utilization in mainland China.

\subsection{Characteristics of coastline fractal dimension change}

Coastline has complex shape and self-similarity; therefore, it is a traditional target of research in fractal science. Calculation of coastline fractal dimension provides an important precondition for accurate measurement of coastline length, promotion of intensive coastline use, and effective coastline protection and management. Xu et al. (2013), Zhu and Cai (2004) and Gao et al. (2011), by calculating fractal dimension, confirmed the fractal characteristics of mainland coastline in China and verified reasons for its regional differences. To assess characteristics of coastline morphological change over a long time span and the impacts of human activities (e.g., land reclamation from the sea) on it, we selected 17 scales (i.e., 250, 300, 400, 500, 750, 1000, 1500, 2000, 2500, 3000, 4000, 5000, 7500, 10000, 15000, 20000 and $25000 \mathrm{~m}$ ) to calculate fractal dimensions of coastlines in mainland China at various spatial units using Grid Method. The results are shown in Figure 2.

In general, fractal dimension of mainland coastline in China exhibited an overall spatial pattern of "north $<$ entirety < south". However, fractal dimension of north has increased continuously over recent years, as a result, the differences between south and north has been narrowed significantly. At provincial level, fractal dimension exhibited a spatio-temporal evolvement from four levels before 2000 to three levels over recent years: fractal dimensions in Fujian and Guangxi were almost the same, which were much higher than that of the whole mainland coastline. Therefore, Fujian and Guangxi constitute Level 1. Level 2 consists of Zhejiang, Guangdong, Shandong and Liaoning, where fractal dimensions approached to the level of the whole mainland coastline, and among them, fractal dimensions in Zhejiang and Guangdong were slightly greater than that of the whole mainland coastline in most phases, while Shandong and Liaoning were slightly lower. Level 3 is composed of Tianjin and Hebei, where fractal dimensions before 2000 were much smaller, however, grew sharply during the past ten years, consequently, Tianjin had risen to Level 1 and even ranked the first in 2014, and as for the fractal dimension in Hebei, although growth rate was slightly slower, it had upgraded into Level 2, resulting in the disappearance of Level 3. The coastline fractal dimensions in Shanghai and Jiangsu were almost the same, which were much smaller than that of the whole mainland coastline, and they remained at the lowest level over the last 70 years. The rise of coastline fractal dimensions in Tianjin, Hebei and Liaoning over the last decade coincided with the large-scale sea reclamation processes in Circum-Bohai Rim coastal zones, indicating that the northward movement of the centroid of coastal development and coastline utilization driven by sea reclamation mainly had altered the entire morphological features of mainland coastline in China by narrowing the difference between south and north. 

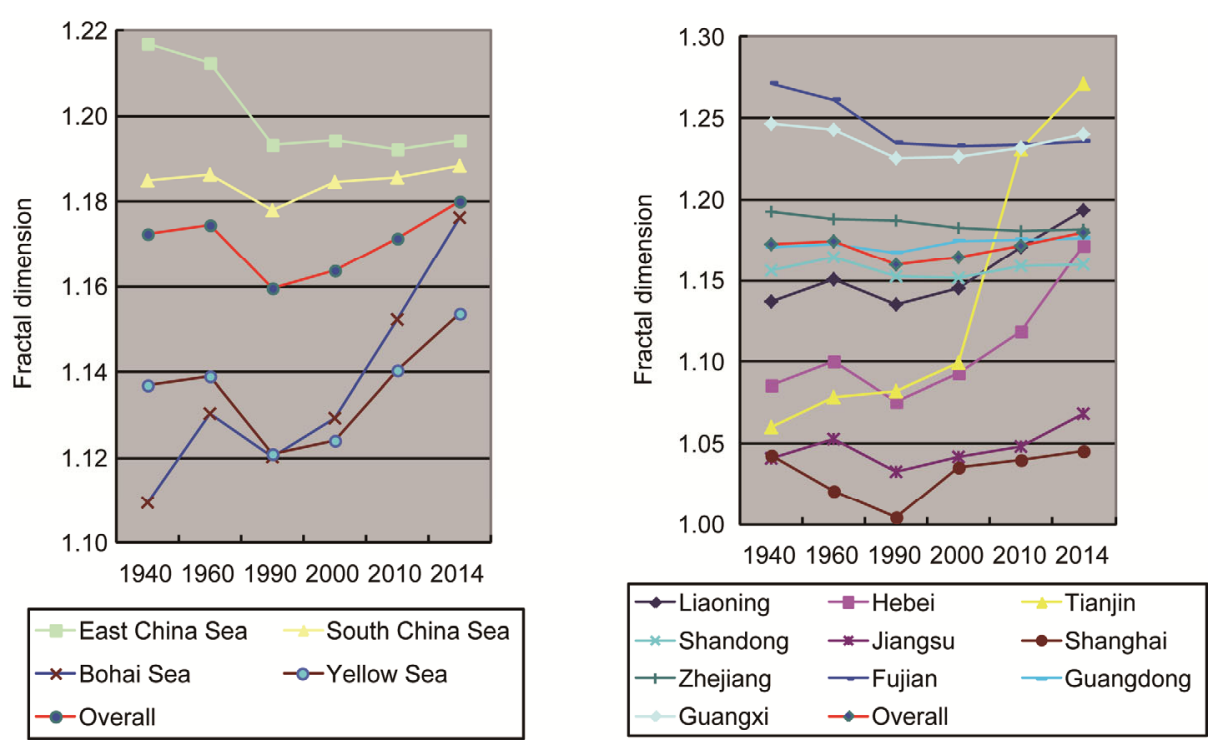

Figure 2 Fractal dimension of mainland coastline in China.

\subsection{Characteristics of coastline change rate}

Coastline change rate (CCR) has been recognized as a highly effective and reliable tool to demonstrate the characteristics of coastline change. Zhang et al. (2004), Kuleli et al. (2011), Romine and Fletcher (2013) used CCR to quantitatively analyze coastline movement in northeast USA, Turkey, and Hawaiian Islands, respectively. National Shoreline Assessment Project, implemented by USGS, also employed CCR to conduct in-depth analysis on coastline change in different regions in USA. End point rate (EPR), average of rate (AOR), linear regression rate (LRR), weighted linear regression rate (WLRR), etc. are the most commonly used CCRs. EPR, which can be calculated for any time span, reflects the general trend of coastline change. WLRR is the slope of regression line fitting to all the coastline positions along each transect which, in this paper, was calculated by using least squares regression and weights referring to the reciprocal of RMSE of point-to-line distances mentioned above, meanwhile, standard deviation, correlation coefficient and confidence interval are also calculated to assess the reliability of change rate (Wu and Hou, 2015). Specifically, a baseline parallel to the general orientation of mainland coastline was constructed at first, and then 12,603 transects perpendicular to the baseline and intersected with six coastlines were casted from north to south at $1 \mathrm{~km}$ interval, and finally, along the transects, EPR during all periods (i.e., the 1940s-1960s, the 1960s-1990, 1990-2000, 2000-2010, 2010-2014, the 1940s-1990, 1990-2014) and WLRR from the 1940s to 2014 with a confidence level of $90 \%$ were calculated. Results are shown in Figures 3 and 4, in which the negative value represents a landward retreat and the positive value means seaward expansion.

The average EPRs during the 1940s-1960s, the 1960s-
1990, 1990-2000, 2000-2010, 2010-2014, the 1940s-1990, and 1990-2014 were $5.28,19.65,14.13,16.46,34.62$, 13.90 , and $18.52 \mathrm{~m} \mathrm{a}^{-1}$, respectively. During different periods over the last 70 years, coastline changes in mainland China were mainly characterized by the seaward expansion, and coastline retreat was a common phenomenon before the 1960s, and yet only occurred in some coasts near northern Jiangsu and Circum-Bohai Rim since the 1960s. The average WLRR of coastline during the 1940s-2014 was $15.81 \mathrm{~m}$ $\mathrm{a}^{-1}$. More than $68 \%$ of coastlines tended to expand toward sea, with a mean WLRR of $24.30 \mathrm{~m} \mathrm{a}^{-1}$; while over $22 \%$ of coastlines tended to retreat toward land, with a mean WLRR of $-3.27 \mathrm{~m} \mathrm{a}^{-1}$; the remaining $10 \%$ of coastlines remained stable and unchanged. Areas where coastline expanded extensively at a fast speed were mainly distributed in the spatially continuous muddy coast, such as eastern Pulandian in Dalian, Liaohe River Delta, Bohai Bay, Yellow River Delta, central Jiangsu, Hangzhou Bay, and Pearl River Delta. The highest change rates occurred in Jiaoliu Island of Wafangdian city in Liaoning Province, Yellow River Delta, Yangtze River Delta, Hangzhou Bay and Zhuhai city. Retreating coastline can mainly be found in sandy coasts in Liaoning, Shandong, Jiangsu, Fujian and Guangxi, especially along the abandoned Yellow River estuary in northern Jiangsu and at the southern coast of Laizhou Bay.

By comparing coastline changes before and after 1990, we found that during the 1940s-1990, the proportion of retreating coastline and expanding coastline were $16.75 \%$ and $43.39 \%$, with a mean change rate of -12.84 and 36.99 $\mathrm{m} \mathrm{a}^{-1}$, respectively; while during 1990-2014, the proportion of retreating coastline and expanding coastline were $15.91 \%$ and $39.35 \%$, with a mean change rate of -4.49 and $48.87 \mathrm{~m}$ $\mathrm{a}^{-1}$, respectively. It can be found that the proportion of expanding coastline during 1990-2014 was slightly lower than 


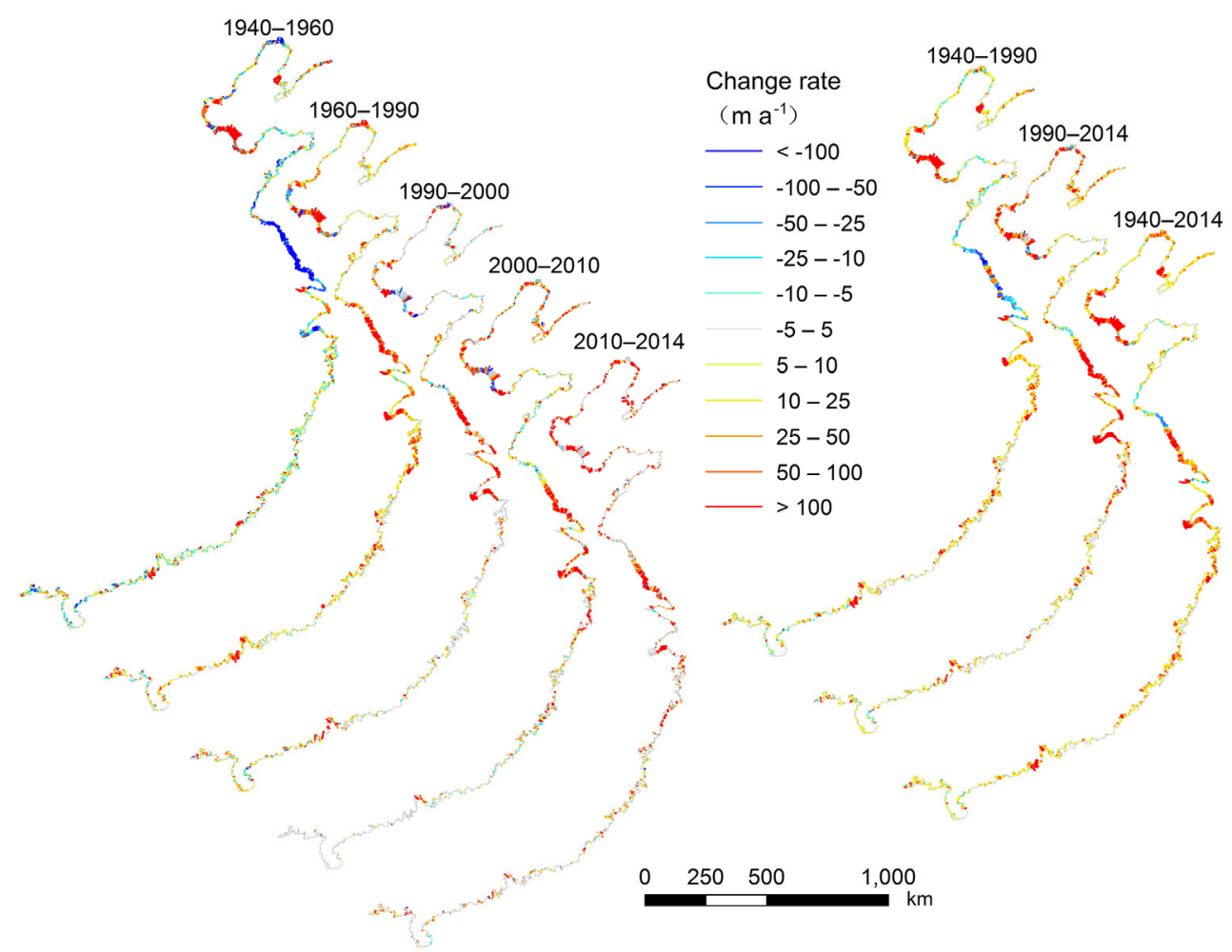

Figure 3 Spatial pattern of coastline change rates on mainland China.
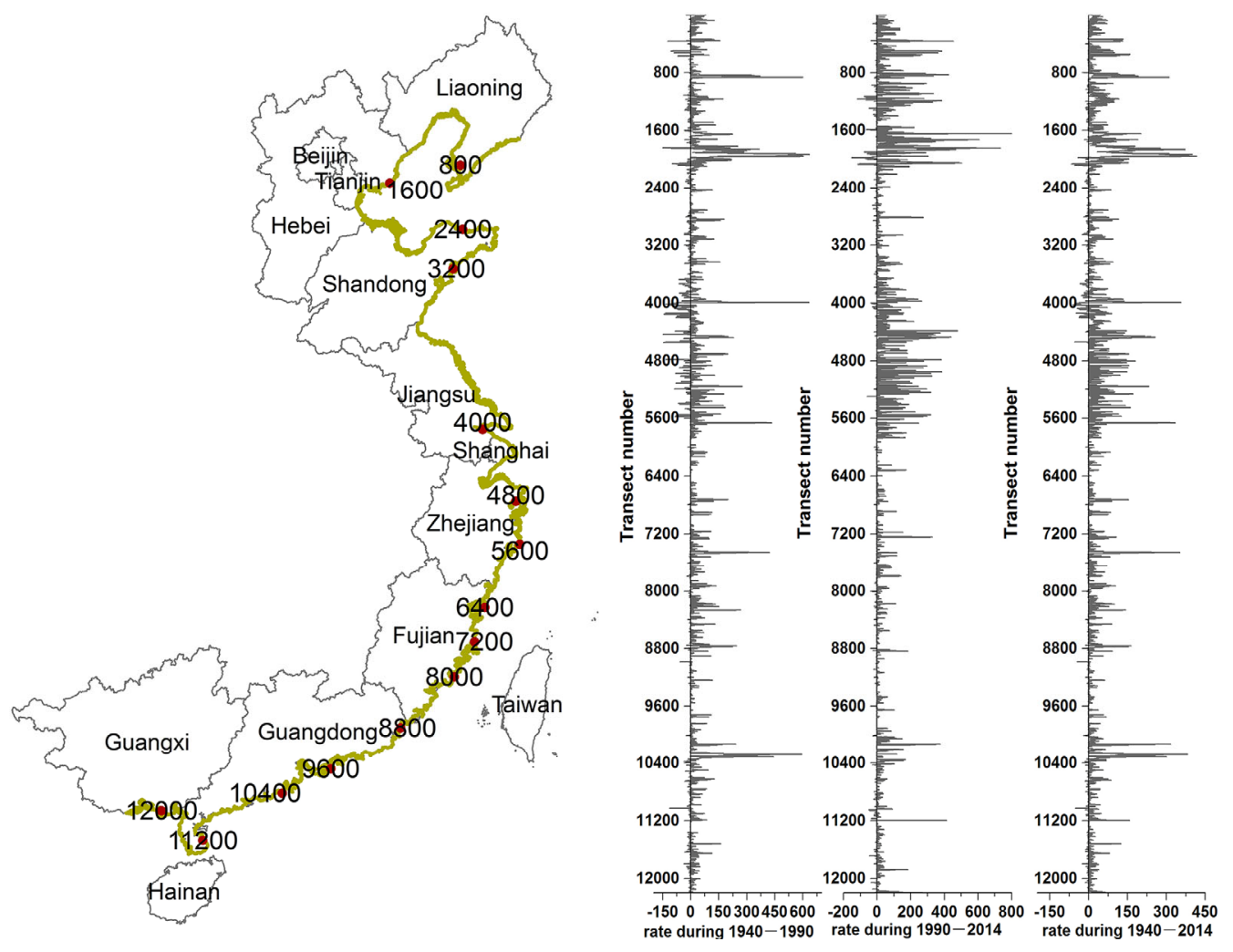

Figure 4 Spatial distribution of mainland coastline transects and coastline change rates.

that during the 1940s-1990, while the mean expansion rate during 1990-2014 was significantly higher than that during the 1940s-1990. This suggests that although the spatial scope of coastline expansion in mainland China since 1990 
tended to concentrate slightly, its expansion rate and intensity grew significantly. During the 1940s-1990, the retreating coastlines were mainly found along coast of Jiangsu and central Zhejiang, with the highest retreating rates occurring near the abandoned Yellow River estuary and the coast from Dongtai to Rudong in Jiangsu; during 1990-2014, the main retreating coastlines expanded northward to the Yellow River Delta, while near the abandoned Yellow River estuary in Jiangsu it tended to become weaker and the trend of coastline change from Dongtai to Rudong reversed due to human activities. During the 1940s-1990, coastline sections that expanded toward the sea were distributed sparsely, while the southern coast of Bohai Bay to Yellow River Delta held the most significant seaward expansion mainly due to the sediment deposition of the Yellow River; during 1990-2014, the spatial distribution of expanding coastlines toward the sea was similar to that during 1940-2014, with two concentration coasts stretching from central Jiangsu to central Zhejiang, and from Bohai Bay to Yellow River Delta, meanwhile, some coasts in Yellow River Delta tended to suffer from erosion.

\subsection{Characteristics of land-sea patterns change}

Coastal erosion, estuary sedimentation, and sea reclamation often result in coastline changes at local and regional scales, which will, in turn, cause land-sea pattern changes at the macro spatial scale. Positional difference of coastline in different periods can clearly reveal the characteristics and main causes of land-sea pattern changes: the spatial domain encircled by coastlines at different phases demonstrates land-sea pattern change in terms of area and size, the positional relationship between earliest and latest coastline reflects directions of coastline change (seaward expansion or landward retreat), and typological changes of coastline further reveal driving forces of land-sea pattern changes. By measuring dynamic changes of land-sea patterns of coastal provinces/municipalities/autonomous regions in mainland China over the last 70 years, and by referring to the length of coastline in the 1940s (groin and jetty are excluded), we defined the growth of land area per unit length of coastline as the "land area growth index (LAGI)". Meanwhile, equivalent distance of land expansion under the assumption that the coastline is fully straight was calculated to reflect the intensity of land area change in different coastal provinces/ municipalities/autonomous regions in mainland China. The results are shown in Table 3.

In general, changes of land-sea pattern were complex over the last 70 years. As for the whole mainland coastal zone and each coastal province/municipality/autonomous region, areas with prominent land expansion and identifiable land retreat coexisted; however, net changes were all characterized by significant land area growth. The net growth in land area of the whole mainland coastal zone in China reached nearly $14.2 \times 10^{3} \mathrm{~km}^{2}$, with an approximate average annual growth rate of $202.82 \mathrm{~km}^{2} \mathrm{a}^{-1}$. Shandong and Zhejiang were the two provinces that hold the most significant net growth of coastal land area, together accounting for $44.80 \%$ of the total net growth of coastal land area in China; followed by Liaoning, Guangdong and Fujian, taken together representing $35.39 \%$ of the total net growth in mainland China; the net growth of coastal land area in other five provinces/municipalities/autonomous regions were smaller, accounting for less than $20 \%$ totally. In terms of LAGI, Tianjin and Shanghai were the most prominent, followed by Hebei, Zhejiang and Shandong. LAGIs of these five regions were higher than $1.22 \mathrm{~km}^{2} \mathrm{~km}^{-1}$, with a maximum value occurring in Tianjin, which reached up to $3.11 \mathrm{~km}^{2} \mathrm{~km}^{-1}$. LAGI of the whole mainland China coastal zone reached up to $0.79 \mathrm{~km}^{2} \mathrm{~km}^{-1}$, converting this value to the equivalent distance of land expansion shows that a total of $18.0 \times 10^{3} \mathrm{~km}$ of coastline in mainland China expanded by $788.65 \mathrm{~m}$ toward the sea, with an average annual expansion rate of over $11 \mathrm{~m} \mathrm{a}^{-1}$. The hotspots and processes of land-sea change in coastal zone of mainland China are mainly characterized as following:

(1) For coastal areas in Jiangsu Province, there's a trade-

Table 3 Changes of land-sea pattern in coastal zone of Mainland China

\begin{tabular}{|c|c|c|c|c|c|c|}
\hline & $\begin{array}{c}\text { Area of land expansion and } \\
\text { sea retreat }\left(\mathrm{km}^{2}\right)\end{array}$ & $\begin{array}{l}\text { Area of land retreat and sea } \\
\text { expansion }\left(\mathrm{km}^{2}\right)\end{array}$ & $\begin{array}{l}\text { Net chang- } \\
\text { es }\left(\mathrm{km}^{2}\right)\end{array}$ & $\begin{array}{l}\text { Coastline length in } \\
\text { the early } 1940 \mathrm{~s}(\mathrm{~km})\end{array}$ & $\begin{array}{l}\text { Land area growth } \\
\text { index }\left(\mathrm{km}^{2} \mathrm{~km}^{-1}\right)\end{array}$ & $\begin{array}{c}\text { Equivalent distances of } \\
\text { land expansion } \\
\left(\mathrm{m} \mathrm{km}^{-1}\right) \\
\end{array}$ \\
\hline Liaoning & 1964.16 & -51.06 & 1913.10 & 2101.94 & 0.91 & 910.16 \\
\hline Hebei & 938.35 & -20.35 & 918.00 & 494.71 & 1.86 & 1855.64 \\
\hline Tianjin & 412.34 & -2.15 & 410.19 & 131.70 & 3.11 & 3114.67 \\
\hline Shandong & 3769.22 & -211.00 & 3558.22 & 2919.49 & 1.22 & 1218.78 \\
\hline Jiangsu & 1242.78 & -507.64 & 735.14 & 1146.06 & 0.64 & 641.45 \\
\hline Shanghai & 444.92 & -2.02 & 442.90 & 189.30 & 2.34 & 2339.74 \\
\hline Zhejiang & 2805.04 & -3.10 & 2801.94 & 2206.12 & 1.27 & 1270.08 \\
\hline Fujian & 1328.66 & -28.18 & 1300.48 & 3499.83 & 0.37 & 371.58 \\
\hline Guangdong & 1934.15 & -122.90 & 1811.24 & 3977.69 & 0.46 & 455.35 \\
\hline Guangxi & 334.19 & -27.84 & 306.34 & 1335.63 & 0.23 & 229.36 \\
\hline Overall & 15173.80 & -976.23 & 14197.57 & 18002.50 & 0.79 & 788.65 \\
\hline
\end{tabular}


off between severe coastline erosion, ecological protection measures (e.g., introduction of Spartina alterniflora for siltation promotion and land protection), engineering measures and sea reclamation. Before the 1960s, erosion issues were widely spread. After that, however, impacts of various protective measures and sea reclamation have exceeded that of natural erosion, resulting in a co-existence of shoreline erosion and land expansion with the overall net growth of land area.

(2) At some large estuaries (e.g., Yellow River estuary, Yangtze River estuary, Liaohe River estuary and Hangzhou Bay), there were complex feedbacks among sedimentation, coastal erosion, sea reclamation, and engineering protection. Over the last 70 years, in terms of land-sea pattern change in estuary, natural factors tended to gradually give their way to human activities that focusing on sea reclamation and engineering protection. For instance, in the Yellow River basin, due to the impacts of climate change, water resources utilization, hydro-technical construction and land use changes, the accretion rate of Yellow River Delta had significantly slowed down since the 1990s, and coastline at northern abandoned Yellow River estuary even suffered severe erosion in recent years.

(3) Sea reclamation tended to become more extensive, faster and more large-scaled, while the economic purpose of sea reclamation had been shifted from salt pans and aquaculture to industrialization and urbanization. Before the 1990 s, the net growth of land area in coastal zones of mainland China mainly resulted from estuary sedimentation, and sea reclamation activities only occurred in or near a few medium and large cities (e.g., Shanghai, Tianjin and Tangshan) or in the form of land-tied island projects (e.g., Changxing Island and Jiaoliu Island in Liaoning, and Huangdao Island in Jiaozhou Bay). After the 1990s, however, the sea reclamation activities had been gradually expanded to other coastal cities, bays and islands. More and more coastal industrial zones and built-up areas emerged. A large number of bays had shrunk due to sea reclamation, and more islands were tied or swallowed up by mainland accordingly.

\subsection{Characteristics of bay area change}

A bay is a water body formed by an indentation of coastline. It links the land and sea, and is known as an area that can be most easily utilized and changed by human beings in coastal zone. Most of the coastal cities worldwide border bays, where coastal exploitation mainly occurs. For this reason, human activities (e.g., sea reclamation and coastline development and utilization) can have a direct and far-reaching impact on the morphology, environment and ecology conditions of bays, which can be reflected most directly by the change of bay area. According to Records of China Bays, there are more than 150 bays with area of more than $10 \mathrm{~km}^{2}$ and approximately 200 bays with area of more than $5 \mathrm{~km}^{2}$ in China, among them, 109 have been recorded in the Records of China Bays. In this study, on the basis of mainland coastlines at six phases, the closure boundary of 93 major bays in mainland China was delineated further in order to acquire data of areas and area changes, which were then aggregated by sea-area as shown in Table 4.

Overall, bay area in each sea-area declined continuously. Over the last 70 years, 93 bays shrank by about $10.09 \times 10^{3}$ $\mathrm{km}^{2}$, with an overall average shrinkage rate of $18.19 \%$ or an average shrinking speed up to $144.20 \mathrm{~km}^{2} \mathrm{a}^{-1}$; among the four sea areas, the shrinkage rate of bays along the East China Sea, $21.01 \%$, was the highest, followed by the Yellow Sea (20.32\%), meanwhile, the figure of Bohai Sea was slightly lower than the overall shrinkage rate of all 93 bays, and the South China Sea was the lowest and far less than the overall 93 bays. Over the last 70 years, the shrinkage mainly occurred before 1990: $56.33 \%, 65.63 \%, 59.46 \%$ and $67.36 \%$ of the shrinkage area in the Bohai Sea, Yellow Sea,

Table 4 Changes of bay area in China

\begin{tabular}{|c|c|c|c|c|c|}
\hline Sea-area & Bohai Sea & Yellow Sea & East China Sea & South China Sea & Overall \\
\hline Amounts of bays & 10 & 29 & 33 & 21 & 93 \\
\hline Bay area in the $1940 \mathrm{~s}\left(\mathrm{~km}^{2}\right)$ & 21934.22 & 3536.56 & 19286.95 & 10744.47 & 55502.20 \\
\hline Bay area in $1960\left(\mathrm{~km}^{2}\right)$ & 20558.92 & 3526.92 & 18947.30 & 10588.15 & 53621.28 \\
\hline Bay area in $1990\left(\mathrm{~km}^{2}\right)$ & 19740.33 & 3064.86 & 16877.14 & 9783.25 & 49465.58 \\
\hline Bay area in $2000\left(\mathrm{~km}^{2}\right)$ & 19431.70 & 3003.95 & 16388.64 & 9445.52 & 48269.80 \\
\hline Bay area in $2010\left(\mathrm{~km}^{2}\right)$ & 18918.14 & 2895.83 & 15710.24 & 9413.12 & 46937.34 \\
\hline Area change during the $1940 \mathrm{~s}-1960 \mathrm{~s}\left(\mathrm{~km}^{2}\right)$ & -1375.30 & -9.64 & -339.66 & -156.32 & -1880.92 \\
\hline Area change during the $1960 \mathrm{~s}-1990\left(\mathrm{~km}^{2}\right)$ & -818.59 & -462.06 & -2070.16 & -804.90 & -4155.71 \\
\hline Area change during $1990-2000\left(\mathrm{~km}^{2}\right)$ & -308.63 & -60.91 & -488.50 & -337.73 & -1195.78 \\
\hline Area change during $2000-2010\left(\mathrm{~km}^{2}\right)$ & -513.55 & -108.11 & -678.40 & -32.40 & -1332.46 \\
\hline Area change during 2010-2014 $\left(\mathrm{km}^{2}\right)$ & -878.78 & -78.06 & -476.32 & -95.66 & -1528.82 \\
\hline Area change during the $1940 \mathrm{~s}-2014\left(\mathrm{~km}^{2}\right)$ & -3894.86 & -718.78 & -4053.03 & -1427.00 & -10093.68 \\
\hline Change speed during the $1940 \mathrm{~s}-2014\left(\mathrm{~km}^{2} \mathrm{a}^{-1}\right)$ & 55.64 & 10.27 & 57.90 & 20.39 & 144.20 \\
\hline
\end{tabular}


East China Sea and South China Sea, respectively, occurred before 1990. The shrinkage rates of bay area varied temporally: the 1960s-1990 and 2000-2010, with the shrinkage speed of 138.52 and $133.25 \mathrm{~km}^{2} \mathrm{a}^{-1}$ respectively, were two peak periods of bay area shrinkage; relatively lower area shrinkage speed was witnessed before 1960, however, it still reached up to $94.05 \mathrm{~km}^{2} \mathrm{a}^{-1}$; after 2010 , it stepped into an unprecedented peak period of bay area shrinkage, with a shrinkage rate up to $382.20 \mathrm{~km}^{2} \mathrm{a}^{-1}$ over the last four years.

At individual bay level, over the last 70 years, more than $18 \%$ bays shrank by more than $50 \%$; more than $27 \%$ bays shrank by $25-50 \%$, about $40 \%$ bays shrank by $5-25 \%$, while less than $15 \%$ bays remained stable and shrank by less than $5 \%$. Related analysis intentionally conducted for the Bohai Sea indicated that its total area (including sea area and islands) had reduced from $81.3 \times 10^{3} \mathrm{~km}^{2}$ in the early 1940 s to $75.6 \times 10^{3} \mathrm{~km}^{2}$ in 2014 , with a shrinkage magnitude of $5.7 \times 10^{3} \mathrm{~km}^{2}$ and a shrinkage rate higher than $82 \mathrm{~km}^{2} \mathrm{a}^{-1}$; The shrinkage rate since 2010 was more astonishing, reaching up to $260 \mathrm{~km}^{2} \mathrm{a}^{-1}$; before 1990, the shrinkage was mainly driven by the development of salt pans, construction of land-tied island projects, as well as accretion of the Yellow River Delta, however, over the last decade, the sea reclamation became the leading cause.

\section{Discussion and conclusions}

Based on remote sensing and GIS techniques, multi-temporal maps and remote sensing images since the 1940s were integrated. With field surveys and in situ measurements that covered the entire coastal zone in mainland China, technological specifications on coastline extraction and classification were established and coastline data at six phases (i.e., the early 1940s, 1960s, 1990, 2000, 2010 and 2014) were created, based on which, spatio-temporal characteristics of mainland coastline in China over the last 70 years were analyzed in terms of coastline structure, coastline fractal dimension, coastline change rate, land and sea pattern, and bay area. The main conclusions are as following,

(1) Coastline structure changed significantly over the last 70 years in mainland China, Both the scale and the speed of coastline artificialization was dramatic. As a result, the proportion of natural coastline declined to $32.92 \%$ in 2014 . In addition, the spatial patterns of coastline structural changes in mainland China were complex, but in general, the intensity of coastline artificialization and utilization was enhanced with a northward movement tendency, especially since 2010, Circum-Bohai Rim had become the hotspot of coastline development and utilization in mainland China.

(2) Coastline fractal dimension was characterized by a general spatial pattern of "north < entirety < south". However, wide-spread and intensive sea reclamation along Cir-
cum-Bohai Rim over recent years had increased the fractal dimensions of coastline in Tianjin, Hebei and Liaoning significantly and continuously, leading to a remarkable diminishing of discrepancy between south and north, which indicated that coastline artificialization mainly caused by sea reclamation and the northward movement of its spatial distribution had significantly changed the fractal characteristics of the entire mainland coastline in China.

(3) The average WLRR in mainland China over the last 70 years was $15.81 \mathrm{~m} \mathrm{a}^{-1}$. More than $68 \%$ of coastlines expanded toward the sea, with an average rate of $24.30 \mathrm{~m} \mathrm{a}^{-1}$; while over $22 \%$ of coastlines retreated toward the land, with an average rate of $-3.27 \mathrm{~m} \mathrm{a}^{-1} ; 10 \%$ of coastlines remained stable. Coastline expansion mainly happened in spatially-continuous muddy coasts and estuaries (e.g., Yellow River estuary), while coastline retreat mainly occurred in sandy beaches (e.g., abandoned Yellow River estuary in northern Jiangsu, parts of coast at the southern bank of Laizhou Bay).

(4) Swings of coastline in mainland China led to complex changes of land-sea patterns; significant land expansion and identifiable land retreat co-exist. The net change of land area, however, presented an increase of nearly $14.2 \times 10^{3}$ $\mathrm{km}^{2}$ with an average annual growth rate of $202.82 \mathrm{~km}^{2} \mathrm{a}^{-1}$, which was equivalent to the $18.0 \times 10^{3} \mathrm{~km}$ mainland coastline expanded to the sea by $788.65 \mathrm{~m}$ overall or with an annual rate of more than $11 \mathrm{~m} \mathrm{a}^{-1}$. More specifically, the sum of net growths of land area in Shandong, Zhejiang, Liaoning, Guangdong and Fujian accounted for more than $80 \%$ of the total land area growth in coastal area of mainland China. In terms of land area growth index, however, Tianjin and Shanghai were the most prominent, followed by Hebei, Zhejiang and Shandong, each of which exceeded $1.22 \mathrm{~km}^{2} \mathrm{~km}^{-1}$.

(5) Over the last 70 years, 93 bays in coastal zone in mainland China shrank by $10.09 \times 10^{3} \mathrm{~km}^{2}$, with an overall average shrinkage rate of $18.19 \%$ or an average shrinking speed up to $144.20 \mathrm{~km}^{2} \mathrm{a}^{-1}$; more than $18 \%$ bays shrank by over 50\%; the 1960s-1990 and 2000-2010 were two peak periods of bay area shrinkage, and after 2010, the shrinkage stepped into an unprecedented peak period; mainly due to the increase of man-made land-tied islands, the accretion of Yellow River Delta, and sea reclamation, the total area of Bohai Sea (including the islands) had decreased by $7.06 \%$ over the last 70 years, with a rate of approximately $82 \mathrm{~km}^{2}$ $\mathrm{a}^{-1}$.

To sum up, coastline change in mainland China since the early 1940s exhibited significant complexity. The rates, patterns and other features of coastline change varied temporally, accordingly, the changes of coastline structure, coastline fractal dimension, land-sea pattern and bay area all exhibited prominent stagewise character; over the last 70 years, the estuary sedimentation, sandy coast erosion, sea reclamation, and engineering protection were believed to be 
the major driving forces of coastline change. However, the physical factors tended to gradually give their way to human factors such as sea reclamation and engineering protection, which had significantly altered the intrinsic evolution processes of China's coastline; especially after the 1990s, sea reclamation became more intensive, faster and more wide-spread, with economic purpose shifting from salt pans and aquaculture to industrialization and urbanization, in addition, sea reclamation had spread to more coastal cities, bays and islands in China. Sea reclamation and coastline change have caused or aggravated many environmental and ecological problems. For instance, the emergence of coastal industrial area and built-up area has put more pressures on coastal environment. Due to sea reclamation, many bays have shrunk and a large number of islands have been engulfed by mainland. The intertidal wetlands diminished quickly, continuously and became more fragmented. Biological invasion became highlighted and biological diversity declined quickly in costal zones. The structures, processes and functions of coastal ecosystems have been seriously damaged. Under such context, it is suggested that in key estuaries, bays and coasts, natural coastline protection and management efforts should be carried out at micro to macro scales by integrating the delineation of marine ecological red lines, marine functions zoning, management of sea area utilization, etc. These efforts should include conservation and restoration of natural shorelines; connectivity restoration and maintenance of the river-estuary-offshore system; comprehensive prevention and control of coastal erosion; protection of inshore and offshore islands; biodiversity conservation in estuaries and bays; environmental and ecological functions remedy of artificial shorelines; integrated coastal management at bay level; etc. Only through these efforts can we significantly promote the protection and effective use of coastline environment and resources, as well as sustainable socio-economic development of coastal zones in mainland China.

Acknowledgements We appreciate the reviewers for their constructive suggestions concerning this paper. This work was supported by the Strategic Priority Research Program of the Chinese Academy of Sciences (Grant No. XDA05130703), the National Natural Science Foundation of China (Grant No. 31461143032) and the Key Research Program of the Chinese Academy of Sciences (Grant No. KZZD-EW-14).

\section{References}

Boak E H, Turner I L. 2005. Shoreline definition and detection: A review. J Coastal Res, 21: 688-703

Cooper M J P, Beevers M D, Oppenheimer M. 2008. The potential impacts of sea level rise on the coastal region of New Jersey, USA. Clim Change, 90: 475-492

Crowell M, Coulton K, Johnson C, Westcott J, Bellomo D, Edelman S, Hirsch E. 2010. An estimate of the U.S. population living in 100-year coastal flood hazard areas. J Coastal Res, 26: 201-211

Cui Y, Chen B J, Chen J F. 2005. Evaluation on self-pollution of marine culture in the Yellow Sea and Bohai Sea (in Chinese). Chin J Appl
Ecol, 16: 180-185

Dar I A, Dar M A. 2009. Prediction of shoreline recession using geospatial technology: A case study of Chennai Coast, Tamil Nadu, India. J Coastal Res, 25: 1276-1286

Feng Y Q, Niu J. 2004. Some problems about coastal environment of China (in Chinese). Mar Geol Lett, 20: 1-5

Gao Y, Su F Z, Zhou C H, Yang X M, Sun X Y, Zhang D D. 2011. Scale effects of China Mainland coastline based on fractal theory (in Chinese). Acta Geogr Sin, 66: 331-339

Gao Y, Wang H, Su F Z, Liu J M. 2013. Spatial and temporal of continental coastline of China in recent three decades (in Chinese). Acta Oceanol Sin, 35: 31-42

Guan L X, Jin B F, Li J Y. 2008. The changing of typical bay coastline in Yantai in recent 20 years (in Chinese). Mar Sci, 32: 64-68

Hou X Y, Wu T, Wang Y D, Xu X L, Chen Q, Yu L J. 2014. Extraction and accuracy evaluation of multi-temporal coastline of mainland China since 1940s (in Chinese). Mar Sci, 38: 66-73

Ji Z X. 1996. The characteristics of coastal erosion and cause of erosion (in Chinese). J Nat Disasters, 5: 65-75

Kish S A, Donoghue J F. 2013. Coastal response to storms and sea-level rise: Santa Rosa Island, Northwest Florida, U.S.A. J Coastal Res, SI: $131-140$

Kuleli T, Guneroglu A, Karsli F, Dihkan M. 2011. Automatic detection of shoreline change on coastal Ramsar wetlands of Turkey. Ocean Eng, 38: $1141-1149$

Kuleli T. 2010. Quantitative analysis of shoreline changes at the Mediterranean Coast in Turkey. Environ Monit Assess, 167: 387-397

Moore L J, Benumof B T, Griggs G B. 1999. Coastal erosion hazards in Santa Cruz and San Diego Counties, California. J Coastal Res, SI: 121-139

Morton R A, Mckenna K K. 1999. Analysis and projection of erosion hazard areas in Brazoria and Galveston Counties, Texas. J Coastal Res, SI: $106-120$

Mujabar P S, Chandrasekar N. 2013. Shoreline change analysis along the coast between Kanyakumari and Tuticorin of India using remote sensing and GIS. Arab J Geosci, 6: 647-664

Peduzzi P, Chatenoux B, Dao H, De Bono A, Herold C, Kossin J, Mouton F, Nordbeck O. 2012. Global trends in tropical cyclone risk. Nat Clim Change, 2: 289-294

Ranasinghe R, Duong T M, Uhlenbrook S, Roelvink D, Stive M. 2013. Climate-change impact assessment for inlet-interrupted coastlines. Nat Climate Change, 3: 83-87

Roeland H, Piet R. 1995. Dynamic preservation of the coastline in the Netherlands. J Coast Conserv, 1: 17-28

Romine B M, Fletcher C H. 2013. A Summary of Historical Shoreline Changes on Beaches of Kauai, Oahu, and Maui, Hawaii. J Coastal Res, 29: 605-614

Slott J M, Murray A B, Ashton A D. 2010. Large-scale responses of complex-shaped coastlines to local shoreline stabilization and climate change. J Geophys Res, 115: F03033

St-hilaire-Gravel D, Forbes D L, Bell T. 2012. Multitemporal analysis of a gravel-dominated coastline in the Central Canadian Arctic Archipelago. J Coastal Res, 28: 421-441

Wu T, Hou X Y, Xu X L. 2014. Spatio-temporal characteristics of the mainland coastline utilization degree over the last 70 years in China. Ocean Coast Manage, 98: 150-157

Wu T, Hou X Y. 2015. Spatial-temporal characteristics of coastline in Jiaozhou Bay during the period of 1944-2012 (in Chinese). Sci Technol Rev, 33: 28-34

Xu J Y, Zhang Z X, Zhao X L, Wen Q K, Zuo L J, Wang X, Yi L. 2013. Spatial-temporal analysis of coastline changes in northern China from 2000 to 2012 (in Chinese). Acta Geogr Sin, 68: 651-660

Yıldırım U, Erdoğan S, Uysal M. 2010. Changes in the coastline and water level of the Akşehir and Eber Lakes between 1975 and 2009. Water Resour Manag, 25: 941-962

Zhang K, Douglas B C, Leatherman S P. 2004. Global warming and coastal erosion. Clim Change, 64: 41-58 
Zhang X H, Sun X M, Yin P, Liu J, Ye S Y, Xia Z, Wang Z L. 2015. Sustainable development of coastal zone based on integreted geologcal investigation (in Chinese). Mar Geol Front, 31: 1-8

Zhu G R, Xu X G. 2011. Research review on environmental effects of land reclamation from sea (in Chinese). Ecol Environ Sci, 20: 761-766

Zhu G R, Xu X G. 2012. Annual processes of land reclamation from the sea along the northwest coast of Bohai bay during 1974 to 2010 (in Chinese). Sci Geogr Sin, 32: 1006-1012

Zhu X H, Cai Y L. 2004. Study on fractal dimension of Chinese coastline and its character (in Chinese). Adv Mar Sci, 22: 156-162

Zhuang Z Y, Liu D Y, Liu C D, Hu G L, Wang L. 2008. Coastal topography survey and mapping (in Chinese). Mar Geol Lett, 24: 25-32 